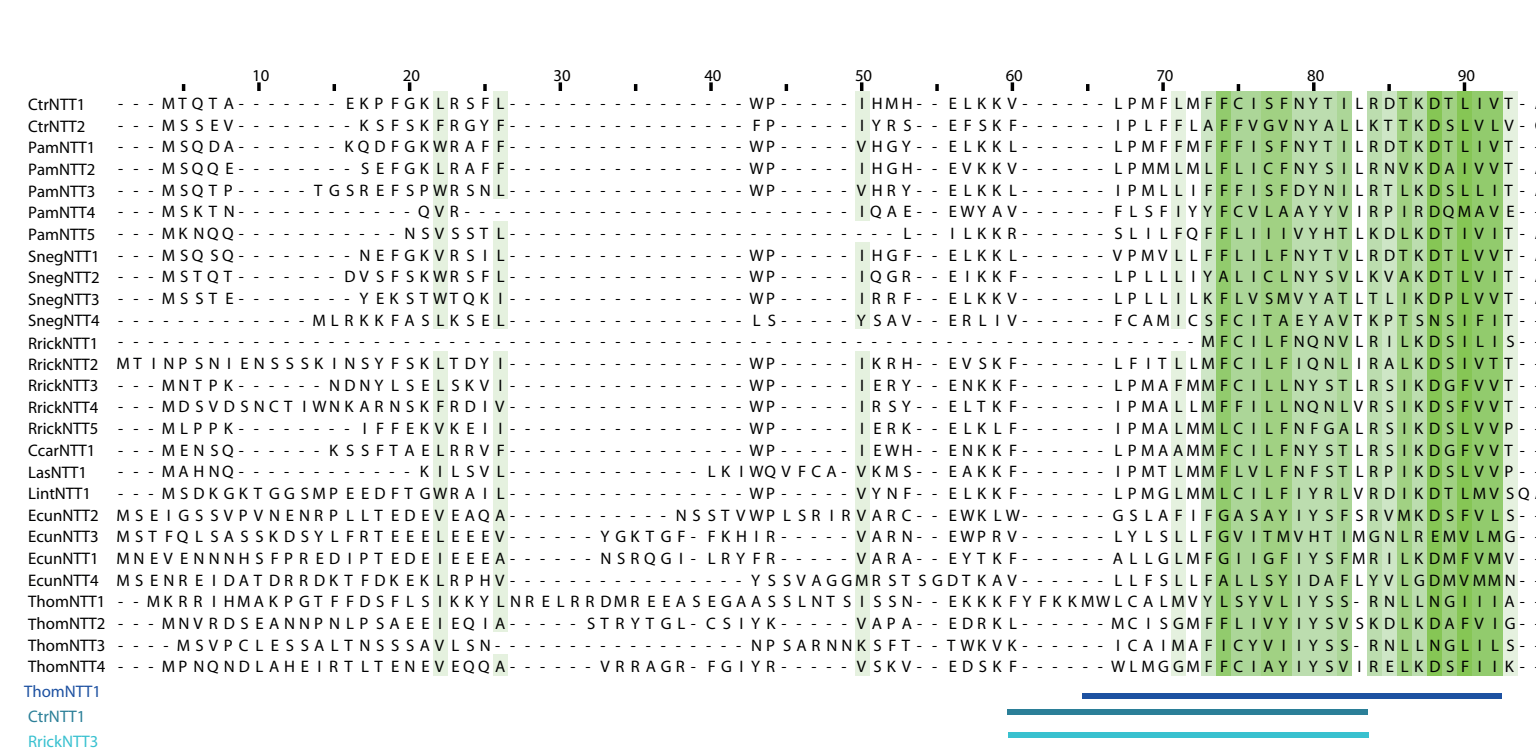

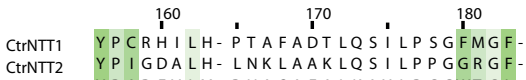

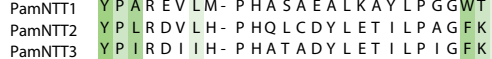

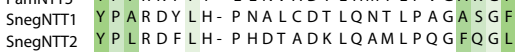

SnegNTT4 GKIP.

RRICNTI1 YPNIHIFHUH DONLADWMERYPH- FKWY

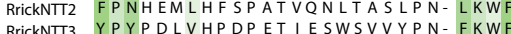

RRickNTIT EPYRDFFHPDPELIKHYYTVLPH-LKWF

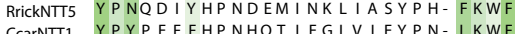

LaSNTI1 YPYRDFLHPSPESIRALASSWPY- LKWE

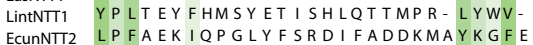

EcunNTा2
EcunNTI3

EcunNTा1
EcunNTा4

LKGYIQKDFYWSRDIFGDGKMESLRI

D.
D.

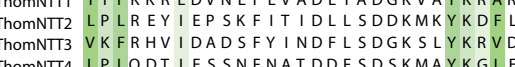

ThomNNIT

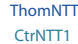

CtrNinT

\section{E245 (At)}

190000

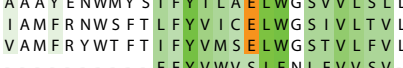

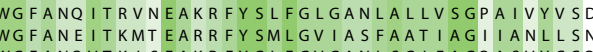

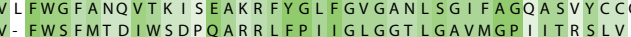
WYWHYTLFYLTAELWSMLILSILFWGYYSDT SLVEAKKFYPLCMEVGNMAGIISGQLSHFLCQ

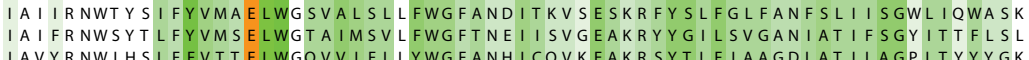

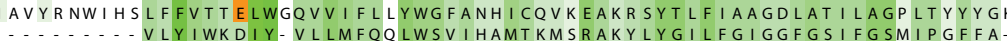

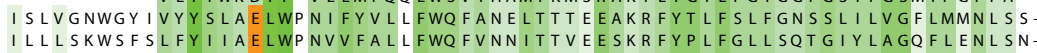

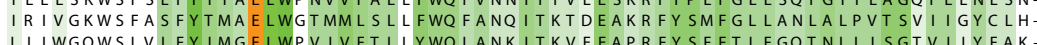
IKIGSOWSYALMYIFAELWSAVVINLMFWOFANHI FDT SSAKRFYPVLGMVGNIGLIIAGSVLVFFSSGO

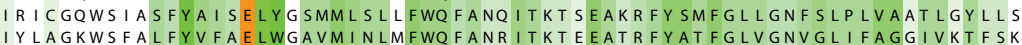

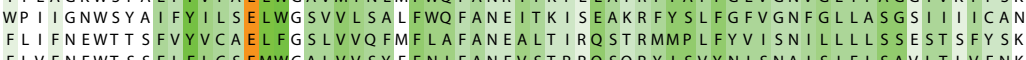
D.
M

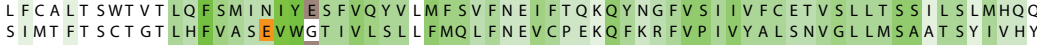

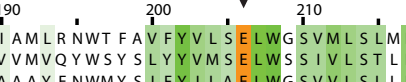

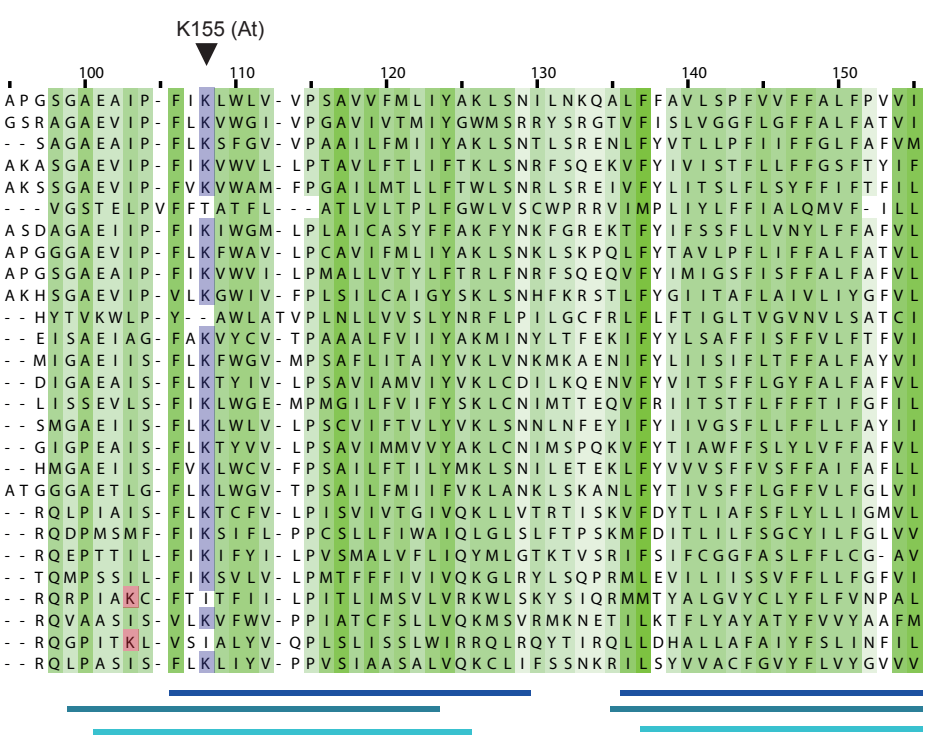

$360, \quad 270,280,290,300$

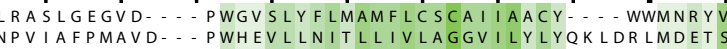

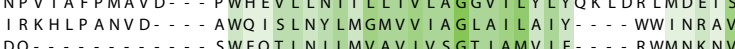

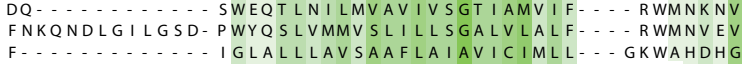

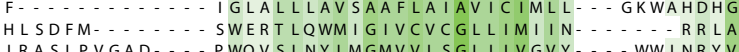

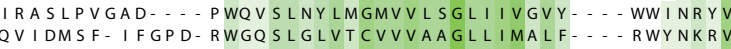

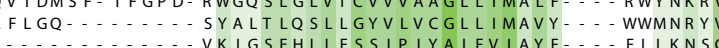

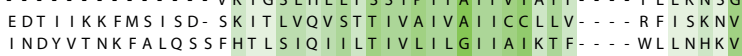

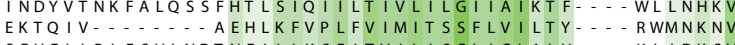

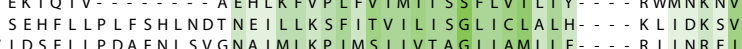
IDSELLPDAFNLSVGNAIMLPPIMSIIVTAGIIAMLLF... RIINRFV
SEINIV.

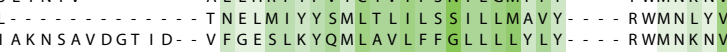

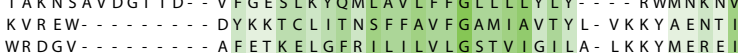

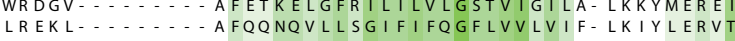

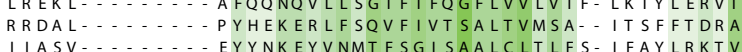

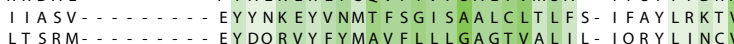

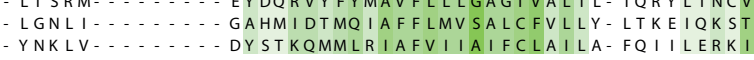

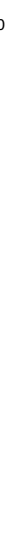

(1)




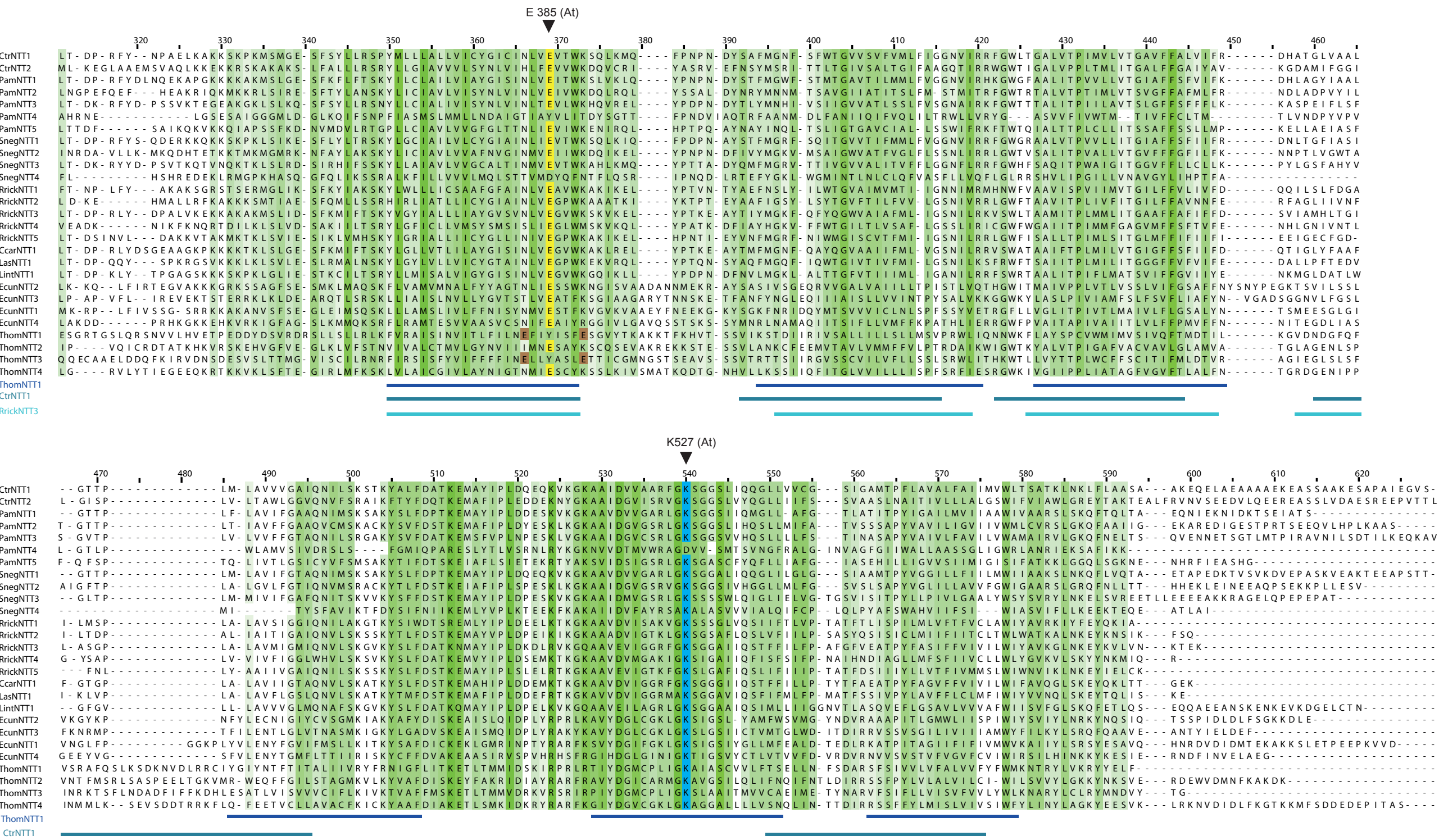

